Article

\title{
A GIS-Based Methodology for Speedy Energy Efficiency Mapping: A Case Study in Bologna
}

\author{
Jacopo Gaspari *(1), Michaela De Giglio, Ernesto Antonini(-) and Vincenzo Vodola \\ Department of Architecture, University of Bologna, Viale Risorgimento 2, 40136 Bologna, Italy; \\ michaela.degiglio@unibo.it (M.D.G.); ernesto.antonini@unibo.it (E.A.); vincenzo.vodola2@unibo.it (V.V.) \\ * Correspondence: jacopo.gaspari@unibo.it
}

Received: 12 March 2020; Accepted: 22 April 2020; Published: 3 May 2020

\begin{abstract}
The paper reports a methodology developed to map energy consumption of the building stock at the urban scale on a GIS environment. Energy consumption has been investigated, focusing on the shift from the individual building scale to the district one with the purpose of identifying larger homogenous energy use areas for addressing policies and plans to improve the quality and the performance levels at the city scale. The urban planning zoning concept was extended to the energy issue to include the energy behavior of each zone that depends on the performance of its individual buildings. The methodology generates GIS maps providing a district scale visualization of energy consumption according to shared criteria. A case study in Bologna city (Italy) is provided. In the specific case, the last update of Emilia-Romagna regional urban planning regulation required a mapping action regarding energy efficiency of homogeneous urban portions defined by the General Urban Plan. The main achieved results are (a) a methodology to identify homogeneous areas for analyzing energy consumption; (b) an updated energy map of Bologna Municipality.
\end{abstract}

Keywords: energy efficiency mapping; energy zoning; energy performance certificate; geographic information system; GIS-based methodology

\section{Introduction}

During the last ten years, a number of regulations were introduced at national and local levels across Europe to acknowledge the EU directives concerning energy efficiency [1,2] and to boost energy savings measures in each member state. In addition to the Italian national regulation, Emilia-Romagna Region has recently updated the Regional Urban Planning Law (LR 24/2017) that states each city of the territory is required to perform a mapping action to detect the low quality stock of existing buildings, particularly the ones not fulfilling the minimum thresholds of energy efficiency and seismic safety (art. 22, par. 6). The request is not associated with any guidelines for performing the mapping action, leaving each municipal administration (MA) free to adopt its own methodology and to display the outcomes accordingly. This makes the possible results often very heterogeneous and hard to compare, depending not only on the adopted approach but also on the quality and reliability of the data to be processed.

This paper summarizes the outcomes of a study that was commissioned by the City of Bologna to define a comprehensive and possibly replicable approach to answer the request while achieving a useful methodology to address the planning actions of the near future, taking into account the energy issue as a key priority in the city development. The proposed approach aims to provide a solution for a quick energy mapping with the purpose of reducing the workload usually needed to face a very time-consuming activity that deals both with dedicated data collection and processing. The method therefore considers the use of already available datasets. As evidenced in the literature [3-8], data processing could take an extremely long time, due to the different data collection criteria and above all 
to the frequent lack of long-term plans for data collection campaigns within the public administrations. This has led to reflect on how mapping is usually conducted, according to the purpose. In most cases, mapping actions are generally based on a precise collection of data related to very appropriate basic units in order to increase the reliability level. However, in this specific case, this would drive the approach to read phenomena at the building scale, rather than at the city scale (which is the typical level of planning actions). Consequently, this study approaches the mapping action accepting some limitations and approximations with the objectives of accelerating the process and providing a comprehensive picture (which can be appropriately updated) in a timely manner of the energy demand at a broader scale.

In order to meet the Bologna Municipality requests, this research looks at energy efficiency from a different perspective, shifting the scale of investigation from the building to the district scale. Energy efficiency is traditionally surveyed at the building scale by analyzing the building envelope, the technical installations and the whole-building energy performance. However, this does not reflect the scope of the Regional Law request, which is basically oriented to understand how energy efficiency is distributed within the urban fabric and to reveal and the energy consumption trend. Thus, the study associates energy mapping with the zoning concept that is traditionally used in the urban planning disciplines $[9,10]$. This requires relating energy demand level to each city block, identified as the minimum unit of the mapping action. The scope is to visualize an energy zoning that, reflecting the current trend of energy demand of the city blocks, will allow MAs to improve their basic knowledge level and to increase the effectiveness of the possible actions to be taken in the near future through the urban regulations. According to this scope and general framework, the research initially investigated input data availability. This was particularly challenging due to the different data sources and related quality as well as to the different update levels of the datasets produced over time.

The outcomes of the study are (a) the definition of a methodological approach for energy mapping based on the energy zoning concept and (b) the visualization of energy zoning of the Bologna city case study via GIS environment.

The study represents a pilot experience that, despite facing several limitations and barriers, tries to offer an original approach to the topic, focusing on a broader vision to support future planning actions and defining a methodological backbone that can be refined and integrated with new data to improve its quality and reliability.

\section{Background Knowledge and State of the Art}

Despite the scientific literature offering a consolidated knowledge on surveying of energy efficiency at the building scale, experiences at district or city scales are still limited and are mainly associated-at least across EU - to wide research projects funded under the umbrella of EU framework programs. Among them, "STEP-UP Strategies Towards Energy Performance and Urban Planning" is one of the first outlining the need to focus on large-scale visions connecting initiatives to support renewable energy source (RES) use with demand trends and player engagement [11]. Dedicated studies operating at the city scale are provided by Caputo et al. [12], Theodoridou et al. [13] and Heiple et al. [14], among others [15].

However, any vision at the urban scale requires data regarding energy consumption to be collected, processed and then displayed with relation to a city map that is typically a georeferenced queryable graphic representation in a geographic information system (GIS) environment (as happens in many other sectors, such as mobility and green infrastructure). According to the most shared definitions, georeferencing is the process of assigning real-world coordinates (i.e., related to an official geographic or cartographic reference system) to a specific object that can be a pixel of raster data [16] or a vector entity such as a point, a line or a polygon [17-19]. All possible input data have to include coordinates or linkable information to available georeferenced geometries, such as cadastral data or street name and building number [20]. The objects can differ in size or typology, affecting the level of detail of the investigation (buildings, cadastral parcels, blocks, etc.). The level of detail consequently has to be 
set according to the mapping purpose and based on the available input data, which must be reliable and accessible. An overall data analysis is needed to set the process and ensure that the outcomes can be clearly understood by the users [21], while adhering to the current regulations regarding privacy in terms of data protection (as data can potentially give information on users' behaviors or living preferences) [22].

GIS is often used in the energy domain to visualize consumption according to specific parcels or filtering data by building typologies [23,24], to address retrofitting actions [21,25], to predict the potential economic and environmental impacts of the adoption of RES use in a specific context $[20,26]$, to plan specific energy infrastructure initiatives [27] or to obtain a projection of atmospheric emissions due to energy consumption [28]. Some studies use GIS technologies to provide energy mapping of built units (individual buildings, blocks, urban fabric portions, etc.) [25,29], offering good evidence of its effectiveness for the purpose and ensuring a precise data georeferencing, a prompt update over time and an easy way to visualize complex information. Since the entailed energy flows are the basic input data needed to draw a GIS map of an area's energy efficiency [23,30,31], the availability and the level of detail of data regarding the energy performance of each considered entity affects both the precision of the model and its reliability [32-34]. According to Lin [25], two main sources can be theoretically used for the scope: on the one side, real energy consumption data can be gained by the energy supplier metering system, assuming that real-time metering devices are installed and that there is a cooperation agreement with the supplier; on the other one, energy consumption can be extracted from energy bills, assuming that users are able to provide this information [32,35]. Unfortunately, there are at least two main critical barriers that obstruct the concrete application of this theoretically optimal approach.

(1) Specific or individual information and data about energy consumption are confidential, and any potential use is regulated by personal data protection [36]. Consequently, they are not easily accessible without the massive and complex involvement of all users potentially involved in the area under investigation [22].

(2) Aggregated data can be more often accessible (under request to the responsible entity); however, the way in which data are aggregated into sets may differ from the physical aggregation of the involved building unit or may be recorded at a scale which does not fit the purpose of the study $[37,38]$.

According to Tronchin and Fabbri [39], energy consumption can be alternatively obtained from energy performance certificates (EPCs), which must be associated to any new or renovated building unit, reflecting the predicted average energy demand based on the technical and constructive characteristics of the building unit according to an official calculation code [40]. EPC data may not exactly match real consumption patterns, and eventual deviations have to be verified by sample tests. Despite being an indirect way to estimate energy consumption, this is a good and more easily accessible option for gaining input data, even if it might not cover the whole stock included within a territorial administrative area. Accurate and systematic information regarding the energy behavior of the building stock including large shares of old and very old buildings is often unavailable in most European urban areas.

Since comprehensive knowledge about energy demand at the urban scale is a strategic element for implementing urban policies in many sectors, several indirect estimation methods have been developed to overcome the lack of direct consumption data. Among them, TABULA-which is the result of an EU-funded project under the IEE program 2009-2012 [41]—established a harmonized catalog of building typologies for the European residential building stock, assigning a typical energy consumption level to each identified category. The typological classification criteria are based on the age of the building, the number of floors and some constructive features that can be identified quite easily by a speedy survey, allowing the application of the methodology to a wide number of cases and keeping the reliability of results within acceptable levels of approximation [42,43]. A good coverage of the required data concerning the involved building stock is an essential factor in limiting the unavoidable imprecision rate of this indirect methodology. Since the results typically refer to the energy demand of a single building, homogeneous coverage is even more relevant when the main 
objective is to analyze the energy consumption at the scale of aggregated buildings, where potential gaps may seriously affect the reliability of outcomes [44].

\section{Data Collection and Methodology}

Even though the present research was generated by a specific request at the regional level, the study was developed within a general theoretical approach with the purpose to offer a "speedy method" to allow MAs to consider the energy performance of the urban stock at a broader scale that can possibly be replicated in different contexts. As evidenced by the scientific literature consulted, a shift from the building to the urban scale in energy consumption analysis is required to better address the future actions in city development and transition to a low-carbon environment.

The study is based on the idea of translating the energy zoning concept into energy maps-to be typically displayed at the district scale-with the purpose of obtaining a tool for easily visualizing energy consumption trends and distribution within the territory under investigation. Accordingly, the GIS environment is considered a powerful way to correlate data and information under investigation with georeferenced data. The GIS environment allows the data to be easily updated and enables the them analysis outcomes on be displayed on the city map.

The methodology was based on two main types of input data strictly related to the building entity that—being the object to which energy performance/demand is associated with—was assumed as the basic unit of the process:

(a) The first required input data typology deals with vector files of the geometrical units to which energy data correspond to. This is a compulsory element needed to locate the basic building unit in the map and univocally associate the related energy data within a GIS environment.

(b) The second required input data typology regards energy consumption of the basic considered units. It has to be noted that this unit may differ from the building as a whole, according to the typology and function.

\subsection{Data Collection}

Vector files have to possibly cover the whole city administrative territory (or at least the one within the investigation boundary). The vector files shall refer to the geometric definition of the buildings, the cadastral parcels, the city blocks, etc., including a set of related topographic information. Generally, the basic unit is associated to individual buildings. These vector files are typically owned by the City Technical Offices for many different purposes and created in different phases according to the need and the scope. It is relevant to note that they frequently present some discrepancies depending on the way in which geometrical data were collected and the files generated. However, considering the whole scale of the process, this can be considered a minor issue.

Energy consumption data represent the key variable of the process and, methodologically speaking, real data are certainly to be preferred, where available, in order to increase the reliability of outcomes. As Figure 1 shows, the availability or unavailability of real data determines the steps of the methodology. Unfortunately, real data are not so frequently available and accessible, as the ownership in most cases is in the hands of the energy supplier, who has to comply with data protection regulations.

Even though specific agreements can solve these limitations (as has happened in some cases), past experiences and the literature [45-48] suggest considering real data to be unavailable. The present study aims to face the most recurring situation where many barriers obstruct the use of these data; thus, keeping in mind the speedy approach of the method, a worst-case scenario is considered. An alternative source of input data is therefore required. Energy performance certificates (EPCs) represent a viable solution. When approaching this data source, the distribution within the city administrative territory has to be carefully checked to make the process feasible. Once input data are secured, the linkage through coordinates or georeferenced information in the GIS environment must be explored, and the coverage within the territory under investigation must be quantified. 
Assuming the use of EPCs as primary data source related to energy demand, the linkage to the vector polygon must be consistent with the administrative entity, usually the cadastral parcel, with EPCs being administratively associated to the building property (which typically refers to the cadastral system). It has to be noted that frequently the cadastral parcel does not perfectly match the building geometrical definition, and the vector files may consequently differ. In the case of more units being included in one building or cadastral parcel, EPCs can be mediated considering the coverage and the boundaries of the selected unit. The decision regarding the file to be used depends on quality of the available files made available by the MA.

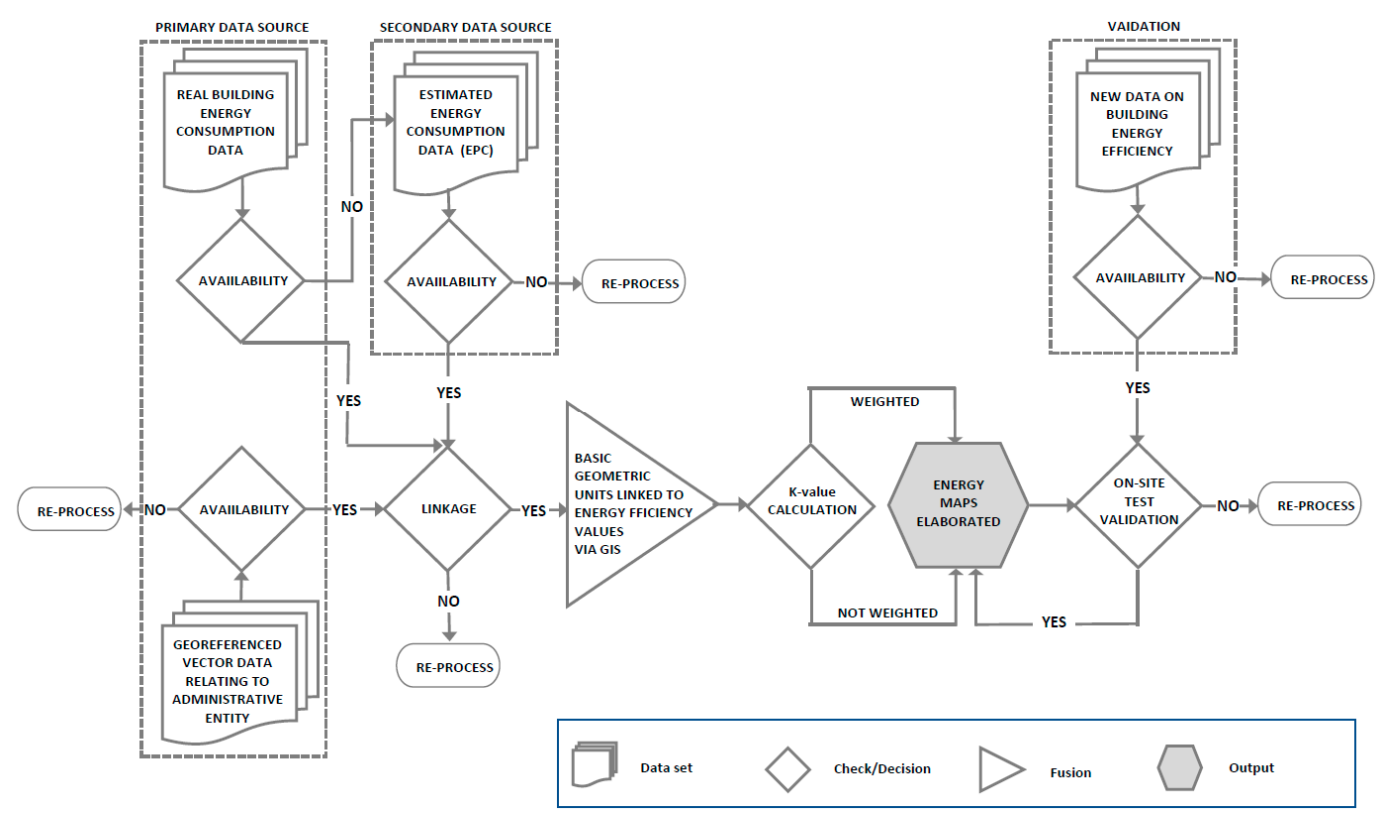

Figure 1. Methodology workflow.

\subsection{Methodology}

The methodology requires obtaining a unique shapefile embedding all original or mediated energy efficiency values univocally associated to the selected basic unit (buildings, cadastral parcels, blocks, etc.).

As the main objective is not to provide a picture of a constellation of individual building energy performance but rather to focus on detecting homogeneous or heterogeneous areas in energy demand within the city territory, a shift from the building or the cadastral parcel geometry to the one of the city block is required. An intermediate required step is to properly define the city block. The definition comes from the urban planning discipline trying to overcome some semantic differences attributed to the urban basic units country by country. Thus, the city block is intended as an ensemble of buildings and in-between spaces (courtyards, private passages, gardens, etc.) delimited in the perimeter by the typical public viability and representing the typical urban unit of larger neighborhoods or districts.

The shift from the basic unit data association to the city block is operated calculating the so-called $\mathrm{K}$ index, which represents an average value obtained from the summation of the energy performance of all the available EPCs included in the city block (mediated according to the related usable area) over the city block surface. The $\mathrm{K}$ index is initially calculated as the weighted average of the total primary energy $\left(\mathrm{E}_{\mathrm{tot}}\right)$ needs of the building units belonging to the same cadastral parcel, with a weight equal to the useful surface. In the case of generalizing K-values from building level to block level, significant differences may occur in the building size and typology within the same block, and the area/size of a building can be used as a weight for calculating the average K-value.

Subsequently, the K-value at the block level is obtained from the simple average of the $\mathrm{K}$ index, previously calculated at the building level (or the cadastral parcel level). Therefore, $\mathrm{K}$ is intended to be a 
geometrical correlation factor between the cadastral parcel unit (or the selected basic unit) and the EPC database (which is also based on a geometrical definition). This allows easily updating the aggregated index if additional data become available within each city block reflecting the improvements made at the individual building scale. At the same time, this allows associating an average behavior with a larger portion of city, providing the MA with a broader picture of the situation sector by sector.

The outcome is a vector map showing the energy efficiency associated to each polygon. The vector data include an attribute table containing all the information related to the considered geometries, which allows extracting specific information related to particular conditions. The map may include some unclassified polygons, due to the eventual lack of input data regarding the EPCs (cadastral data, geometric data), that appear as neutral but may be updated when the related input data become available. The energy use intensity can be associated to other maps (typologies, functions, density, etc.) in order to better define specific improvement and development policies, depending on the MA programs.

The novelty of the proposed methodology does not deal with data processing-as the intention was to adopt currently available tools to facilitate the replication and adoption of the process-but lies in the approach to mapping (from the building level to the block level) considering the urgency of a broader vision and the need of a less time-consuming process to support decision-makers and planners in driving measures at the city level. The contributions offered by the proposed methods to those operating in this sector deal with being a feasible process based on available resources in a quite speedy way, a viable solution to overcome frequent existing barriers (e.g., limited access to real data, limited data coverage, limited precision of vector files) and a replicable process in different contexts using quite comparable input data. The proposed methodology reflects a very flexible approach, designed to be easily replicated, since both the input data processing and the scale of representation can be modified, consequently adapting the process to the local framework in order to achieve comparable maps displaying the available data content [49].

Even though the methodology may suffer from some approximations and loss of data (mainly due to lack of a complete coverage), it is designed to easily accept adaptations or updates. The increase of data availability and accuracy can improve the quality of outcomes and mapping process definition, giving the MAs a tool to quickly monitor the mid- to long-term progress and impacts of the adopted policies.

In order to validate the process and the obtained map, different input data must be assumed [20] that possibly adhere to real energy consumption. Considering the abovementioned limitations and the complexity of a large-scale process, the validation step can be performed on sample test sites where information and input data can be more easily accessible and available. A case study application has been performed within the city of Bologna.

\section{Bologna Case Study Application}

According to the request of the MA, the defined methodology has been applied to the case study of Bologna, a medium-large-size city located in lower northern part of Italy (Figure 2). With approximately 400,000 inhabitants ( 1 million considering the whole metropolitan area), Bologna is the seventh most populated Italian city [50]. As the capital city of Emilia-Romagna Region, it has an extent of approximately $140 \mathrm{~km}^{2}$ and a density of 2780 inhabitant $/ \mathrm{km}^{2}$ [50] Bologna is renowned for having one of Italy's largest and most well preserved historical city centers. 


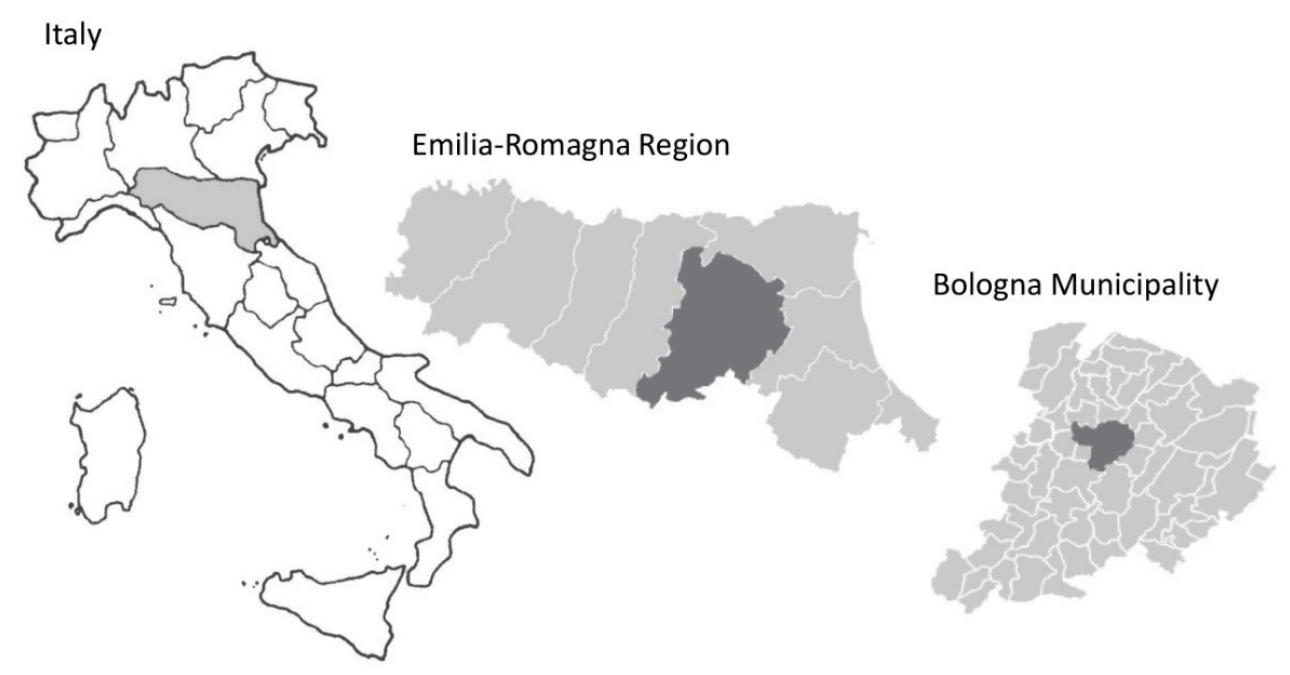

Figure 2. Bologna Municipality (Italy) location.

The urban plan adopted in the late nineteenth century drove the expansion of the city outside the medieval wall ring influencing the city development since the end of the Second World War, when large portions of urban fabric mixing residential and industrial settlements were newly built on the north, east and west sides, often creating dense districts [51-53]. A new general urban plan was adopted in the early 1960s to address further expansions and to mitigate the lack of green and district infrastructure. During the last twenty years, the city of Bologna was characterized by a less intensive building activity more oriented to meet the goals and the key elements of sustainable construction and therefore acknowledging the national regulations that were introduced to adhere to the EU directives. Furthermore, in 2015 Bologna adopted the so-called Bologna Adaptation Plan as the result of the BLUE AP project (Bologna Local Urban Environment Adaptation Plan for a Resilient City), funded by the EU under the umbrella of LIFE+ program (LIFE11 ENV/IT/119), to address future development actions towards more resilient and less energy-consuming solutions to cope with climate change [54].

The update of the Regional Law on Urban Planning (LR 24/2017) therefore represents the last step of a process deeply focused on properly facing the challenge of greatly decreasing energy demand in the coming decades. The study reported in this paper represents the outcome of an intense dialogue with the Bologna administration during the last year and a half.

\subsection{Preliminary Phases}

During the preliminary phase, the research team and the MA discussed the possible data sources according to availability and accessibility. Real energy consumption data were assumed as unavailable, as this data typology is not owned by the MA and there is no specific agreement with the energy supplier to access it. The initial request of the MA was to estimate the energy performance level considering the year of building construction and both the surface (S) and the volume (V) of each building. The first attempt of association using the TABULA database [55] gave unsatisfactory results, demonstrating that the proposed methodology requires input data regarding energy consumption. Once this was clarified and the MA commitment in this direction was obtained, some key priorities were defined: (a) the level of knowledge about energy performance had to be explicitly related to the basic unit in terms of input data to be made available; (b) a stable and possibly univocal definition of the polygon, corresponding to the building unit, had to be achieved.

Thus, EPCs were assumed as input data regarding energy consumption, being aware that they could not completely cover the whole building stock but having in mind that they are continuously updated and implemented, allowing the methodology to be constantly refined and increased in coverage when new input data become available. 
The MA agreed to provide the most updated vector files, regarding both the buildings and the blocks, as well as the EPCs concerning the buildings located within the city's administrative boundaries.

The EPCs files were collected in separate sets, organized according their issuing period, namely 2009-2015 (EPCs from 2009 to 1 October 2015-81,350 records), 2015 (EPCs from 1 October 2015 to 31 December 2015-3265 records), 2016 (full year-11,649 records), 2017 (full year-9973 records) and 2018 (full year-5624 records). The distinction within 2015 is due to the introduction of a new regulation in force from 1 October 2015 (Ministerial Decree 26/06/2015) concerning [56] (a) new elements (such us aeration, air-conditioning, artificial lighting) to be included within the Global Energy Performance index calculation (later called $\mathrm{Ep}_{\mathrm{tot}}$ ) and (b) the use of $\mathrm{kWh} / \mathrm{m}^{2} *$ year as energy performance unit of measurement for all building typologies (while before 1 October 2015, the index was referred to as the volume unit $\left(\mathrm{KWh} / \mathrm{m}^{3 *}\right.$ year) for nonresidential buildings (called E1, including several subclasses)). Due to data protection regulations, EPCs were provided without including the building address and street number, only including cadastral data for GIS linkage purpose.

An EPC database, with cadaster and full location files, was provided to the Municipality by the Emilia-Romagna Region (who is the subject in charge of collecting these data) for validation purpose in sample areas only and with a strict nondisclosure agreement. Thus, the entire first stage of the study was carried out referring to cadastral data only.

\subsection{First Stage}

The first stage of the process aimed at computing the energy efficiency $\mathrm{K}$ indexes to be associated with the map geometries. This index refers to the E $p_{\text {tot }}$ values and the total usable area belonging to each individual cadastral parcel. The index is thought to mediate the potential lack of some EPCs in the same cadastral parcel (the lack could be amended in the future when the missing data become available). The calculation process allows monitoring the loss of data in each cadastral parcel. The $\mathrm{K}$ indexes were calculated based on EPC data and using Microsoft Excel and QuantumGIS, according to the following steps:

(1) Each EPC dataset was filtered to delete records (almost 3\%) including errors (i.e., zero or missing value for heated volume field, usable area field, cadastral parcel field, or formally incorrect values, etc.)

(2) The EPC datasets were merged into a single file (111,861 records), detecting and erasing EPC duplicates (almost 1\%) associated to the same building unit to keep the most updated one.

(3) E $p_{\text {tot }}$ values determined before 1 October 2015 for E1 building class were converted to express the unit measure in usable floor area instead of heated volume (this is to amend the change in the regulation that occurred).

(4) E $\mathrm{p}_{\text {tot }}$ values (almost 1.5\%) over the thresholds of $500 \mathrm{KWh} / \mathrm{m}^{2} *$ year for residential buildings and $800 \mathrm{KWh} / \mathrm{m}^{2 *}$ year for nonresidential buildings were excluded, assumed to be out of scale based on regional guidelines and the literature [57]. At this stage, the total number of EPCs suitable for $\mathrm{K}$ index calculation shrunk to 106,469 .

(5) As reported in the literature [58-63], most of energy efficiency indexes take into account the building envelope characteristics, the heating/cooling and services systems and the concurrent features in order to determine the energy demand. EPCs comply with calculation standards, and the proposed $\mathrm{K}$ index aims to mediate the sum of energy performance of the basic units within each cadastral parcel. The energy efficiency K index was calculated as follows (Equation (1)):

$$
\mathrm{K}=\frac{\sum\left(\mathrm{Ep}_{\mathrm{tot}} \times \text { Usable area }\right)}{\sum \text { usable area }}
$$

where $\mathrm{K}\left(\mathrm{KWh} /\left(\mathrm{m}^{2}\right.\right.$.year $\left.)\right)$ is the energy efficiency index, $\mathrm{E} \mathrm{p}_{\text {tot }}\left(\mathrm{KWh} /\left(\mathrm{m}^{2} \cdot\right.\right.$ year $\left.)\right)$ is the energy efficiency value for single unit with EPC, $\sum$ usable area is the total usable area $\left(\mathrm{m}^{2}\right)$ or the sum of all the useful 
surfaces with available EPCs within the same cadastral parcel and Usable area $\left(\mathrm{m}^{2}\right)$ is the single unit floor surface.

(6) $\mathrm{K}$ index values were checked to delete eventual errors (less than $1 \%$ ).

The obtained $\mathrm{K}$ indexes computed for each cadastral parcel were then ready to be transferred to the GIS environment. For this purpose, the merged EPCs file (steps 2-4) with 106,469 records, the cadastral parcel vector data (73,984 polygons) and the building vector data (41,010 polygons) were used.

The obtained $\mathrm{K}$ index can be consequently associated directly to the cadastral parcel or to all the buildings included in it.

In the first case, a one-to-many relationship was established between the cadastral parcel attribute table (A-father) and the EPC table (B-sons). As the primary key is a unique identifier, the foreign key can reliably reference it as one record [64]. The A primary key was obtained by joining the cadastral sheet and the cadastral parcel fields.

In the second case, a new one-to-many relationship was added. It was established between upgraded cadastral parcels vector (A) and building vector (B). All entities to which an EPC is not associated (such as churches, historic monuments, kiosks, etc.) were previously excluded.

Finally, to add the $\mathrm{K}$ index field to building vector, the join function was applied between the building attribute table and the cadastral parcels attribute table.

\subsection{Second Stage}

In order to adapt the model for urban planning purposes, the energy consumption trends were projected at the urban fabric level in a second stage. The coefficient $\mathrm{K}$ was mediated at the block scale. The block is defined as a portion of urban fabric surrounded by public streets whose boundaries are classified from an administrative point of view [65]. However, other scale options might be considered in different contexts according to specific characteristics and goals. The decision was discussed and agreed upon with Bologna MA. This does not limit the replication elsewhere nor the validity, as both are mainly dependent on the selected data source availability. The file containing the geometrical definition of the blocks was provided by Bologna MA. The process was managed by QuantumGIS software according to the following steps:

(a) The block identification code was associated to each building by using the position tool.

(b) For each block, the mean K-value (starting from K-values of buildings included of the same block) was calculated (K $\mathrm{KLOCK}_{\text {index). }}$

(c) The new one-to-many relationship was accordingly applied. It was established between block vector (A) and building vector (B), so that a single record of the block attribute table (A) matched many rows in building attribute table. Then, the join function was applied between the block attribute table and the building attribute table to add the $\mathrm{K}_{\mathrm{BLOCK}}$ index field to the block vector.

(d) Finally, the EPC number used in the calculation of the $\mathrm{K}_{\mathrm{BLOCK}}$ index for each individual block was calculated. Consequently, the information was transferred to the map using the centroids of the polygons corresponding to the blocks.

As explained in the methodology paragraph, the area/size of a building can be used as a weight for calculating the average K-value, and the option to calculate a weighted average K-value was indeed considered in an early stage. A test in a sample portion leading to a difference of less than $5 \%$ was discussed with Bologna MA who explicitly required not to weight the K-value, keeping it directly linked to the EPC values of the units included in the block. Even though the EPC availability may not cover all buildings in the block at the moment, Bologna MA and Emilia-Romagna Region are boosting the update of EPCs; therefore, the integration of new certificates will certainly increase the accuracy in the future. Thus the EPC coverage can quickly reach $100 \%$ in the coming years, reflecting the situation within the block and the buildings and allowing the MA to monitor the progress in this direction. After a long discussion with the MA about which option would better fit the specific case, the proposed methodology was confirmed. 


\subsection{Validation}

In order to validate the energy maps generated by the described methodology, a sample area was selected to apply the assessment procedure. The site is named "Bolognina" and is made of large blocks, mostly arranged according to a very regular grid of plots, located in the north side of Bologna, near the railway station. As real data on energy consumption are unavailable (typically owned by energy suppliers and strongly covered by data protection regulation), the validation used a new set of EPCs that were provided for this stage only with the full location address (street name and the street number) for each individual building unit. Similar to the previous stage, data are organized in the following separate files: 2009-2011 (full years), 2012-2013 (full years), 2014-2015 (EPCs until 30 September 2015), 2015-2019 (EPCs from the 1 October 2015). Consequently, the following preprocessing steps were needed:

(1) Each EPC dataset was filtered to delete records (almost 4\%) including errors (i.e., incorrectly written values in the E $p_{\text {tot }}$ field and in address or street number field, etc.)

(2) The EPC datasets were merged into a single file (126,383 records), detecting and erasing EPC duplicates (almost 1\%) associated to the same building unit to keep the most updated one.

(3) E $p_{\text {tot }}$ values determined before 1 October 2015 for E1 building class were converted to express the unit measure in usable floor area instead of heated volume.

(4) $\mathrm{E} \mathrm{p}_{\text {tot }}$ values (almost $1.5 \%$ ) over the thresholds of $500 \mathrm{KWh} / \mathrm{m}^{2}$ * year for residential buildings and $800 \mathrm{KWh} / \mathrm{m}^{2 *}$ year for nonresidential buildings were excluded, assumed to be out of scale based on regional guidelines.

Then, the validation procedure for the Bolognina sample area was performed, including the following steps:

(1) The specific EPC records were extracted according to Bolognina street locations. The address line was corrected using semi-automatic procedures to make the addresses consistent with those reported in the street number vector file. Address duplications within the street number vector file were deleted to obtain unique values for this field.

(2) The Ep tot mean value was calculated starting from EPCs having the same complete address. This step makes the validation comparable with the procedure used in the calculation of the K indicator.

(3) A new one-to-many relationship was created between street number vector (A) and EPC table (B) to match a single record of the street number attribute table (A) with many rows in EPC table. The join function was then applied between the street number attribute table and the EPC table to add the $E p_{\text {tot }}$ mean field to the street number vectors.

(4) The Eptot mean value between the street numbers included in the same block was calculated within the upgraded street number vector.

(5) The E $p_{\text {tot }}$ mean block value, representing all the street numbers included in the same block, was associated to the block polygons through the attribution for position tool.

\section{Case Study Results}

The described methodology and related procedures produced vector files containing all the necessary information to represent the estimated energy consumption values on a GIS-based map. Graphical representation can be displayed according to three different scales: buildings, cadastral parcels and blocks. In order to improve map readability, a color palette that varies from green to red-associated to the best and the worst conditions, respectively-was applied. The color scale was divided into six classes from $0-100 \mathrm{KWh} /\left(\mathrm{m}^{2} \cdot\right.$ year) to greater than $300 \mathrm{KWh} /\left(\mathrm{m}^{2} \cdot\right.$ year) (Table 1$)$. The cartographic reference system of all maps is ETRS89/UTM 32N. The original building vector file contained 41,010 buildings and represents the whole city territory at building scale definition. 
Table 1. Consumption classes according to the energy map visualization.

\begin{tabular}{|c|c|c|}
\hline & Class & $\mathrm{K}\left(\mathrm{kWh} / \mathrm{m}^{2} \cdot\right.$ Year $)$ \\
\hline 1 & & $0-100$ \\
\hline 2 & & $100-150$ \\
\hline 3 & & $150-200$ \\
\hline 4 & & $200-250$ \\
\hline 5 & & $250-300$ \\
\hline 6 & & $>300$ \\
\hline
\end{tabular}

The uncolored buildings are those not useful for the scope (such as canopies, abandoned or dismissed buildings, kiosks, barracks, etc.) or belonging to specific categories like historical monuments or those not included due to data unavailability or errors. The final file considers 37,651 buildings of which 19,311 (51.3\%) are properly classified according to the EPC criteria (Table 2). Figure 3 provides a detailed portion of $\mathrm{K}$ index energy map at cadastral parcels scale.

Table 2. Summary of resulting data.

\begin{tabular}{ll}
\hline Number of buildings included in the vector file & 41,010 \\
\hline Number of buildings/parcels considered for the scope & 37,651 \\
\hline Number of buildings/parcels related to K index values & 19,311 \\
\hline
\end{tabular}

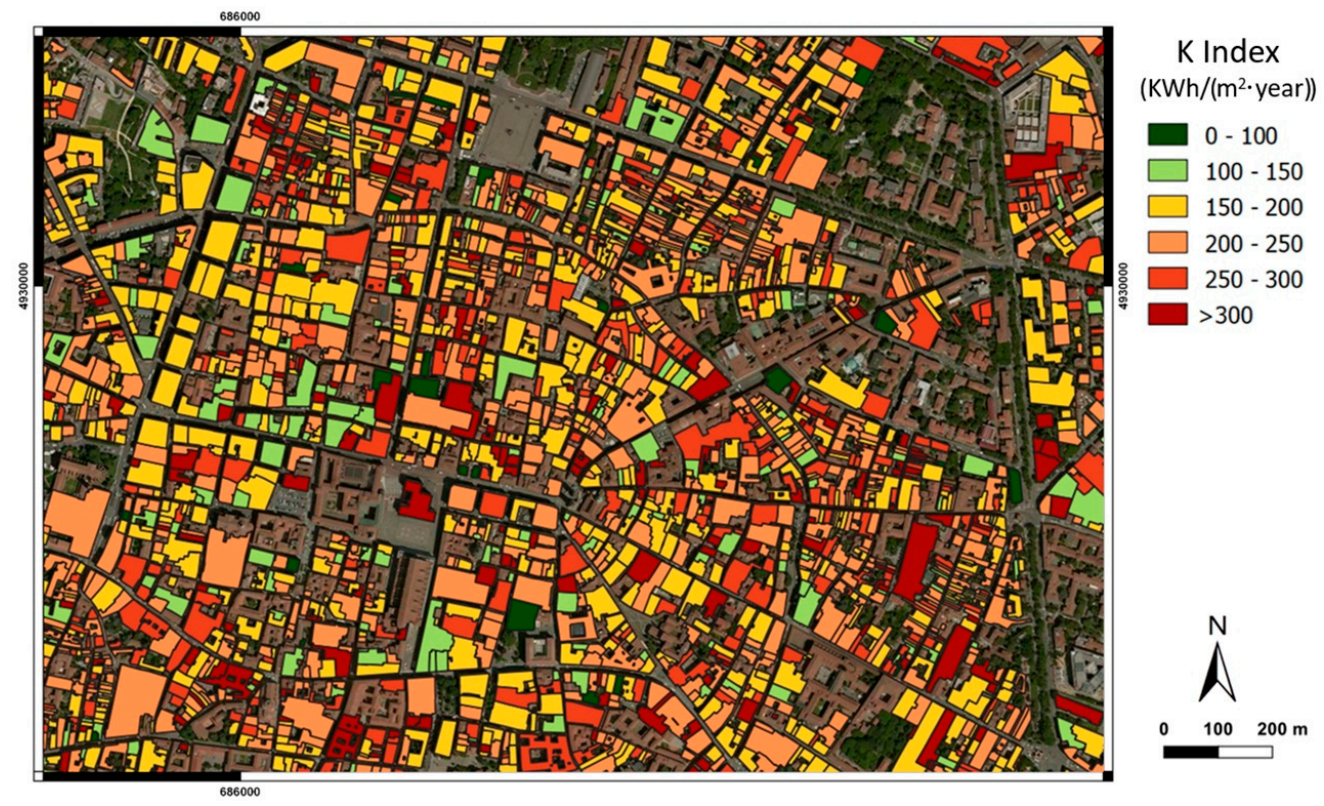

Figure 3. $\mathrm{K}$ index map at cadastral parcel scale. Bing aerial imagery is used as the base map.

Figure 4 offers an overview of the $\mathrm{K}$ index map at block scale (K $\mathrm{K}_{\mathrm{BLOCK}}$ index) considering the entire extent of Bologna city. Approximately $12 \%$ of the blocks (283) resulted as not being classified. The fourth class (orange $200-250 \mathrm{KWh} /\left(\mathrm{m}^{2}\right.$.year)) includes the highest number of polygons (960). 


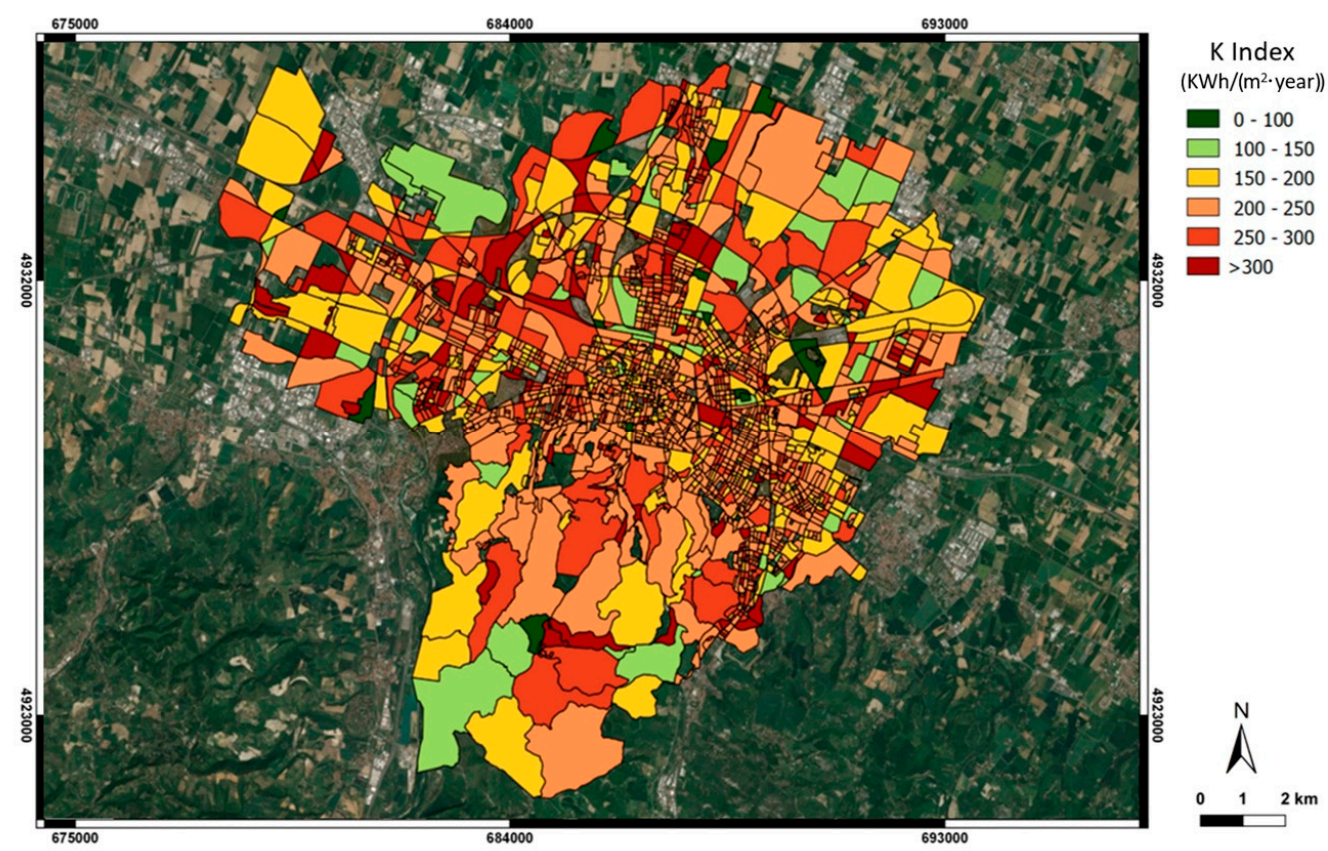

Figure 4. $\mathrm{K}$ index map at block scale ( $\mathrm{K}_{\mathrm{BLOCK}}$ index). Bing aerial imagery is used as the base map.

Figure 5 provides the portion of the map at the block scale corresponding with the sample site used for validation purpose. The same color palette used for the $\mathrm{K}$ index maps was applied. For each block, the number of EPCs with complete address, available for the E $\mathrm{p}_{\text {tot }}$ mean value calculation, is reported.

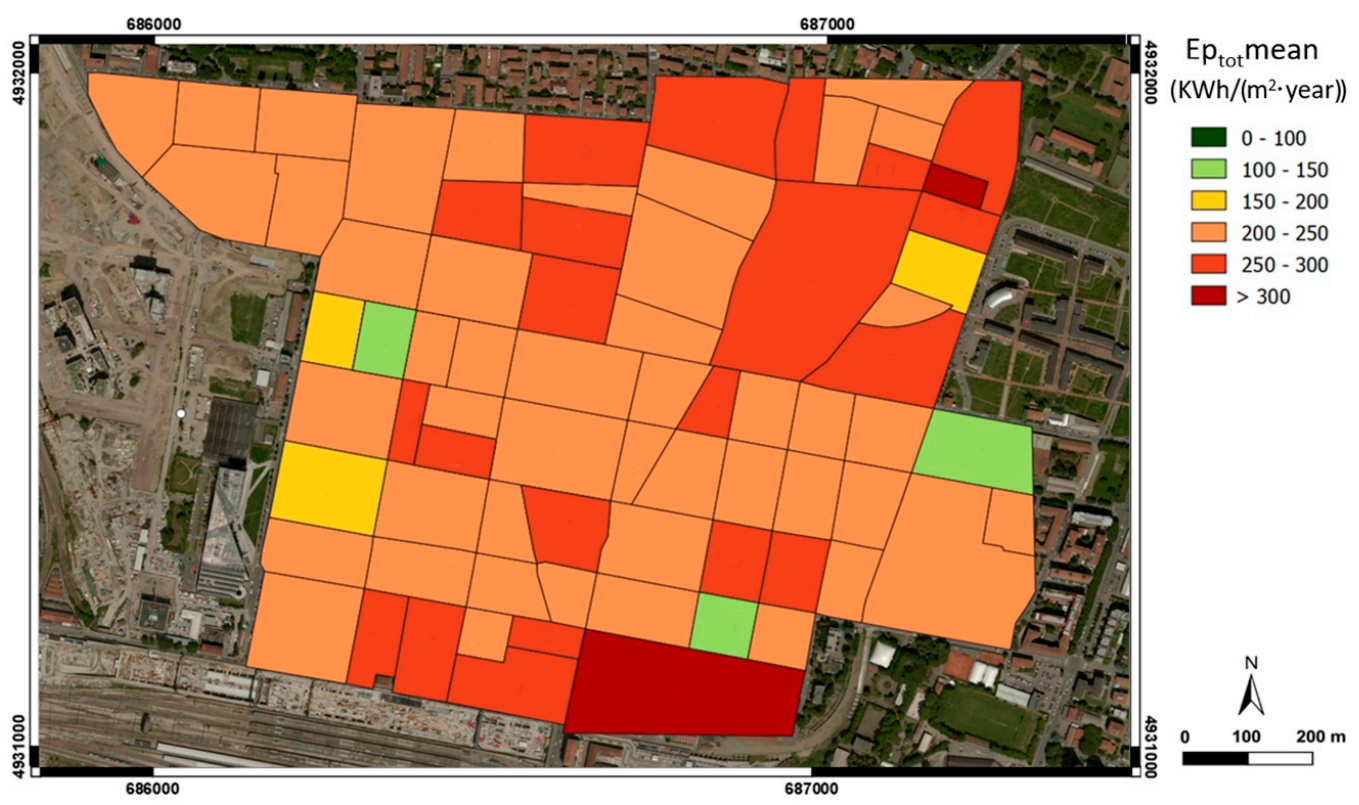

Figure 5. E $\mathrm{p}_{\text {tot }}$ mean value map corresponding to the validation area (Bolognina) at block scale. Bing aerial imagery is used as the base map.

Figure 6 provides a detailed map of the $\mathrm{K}$ index $\left(\mathrm{KWh} /\left(\mathrm{m}^{2} \cdot\right.\right.$ year $\left.)\right)$ in Bolognina district sample site. The blocks requiring further refinement to be classified through validation procedure are highlighted with a cyan line. The $\mathrm{K}$ index classification corresponds in 64 out of 80 blocks, while in the other ones the difference never exceeds one class. 


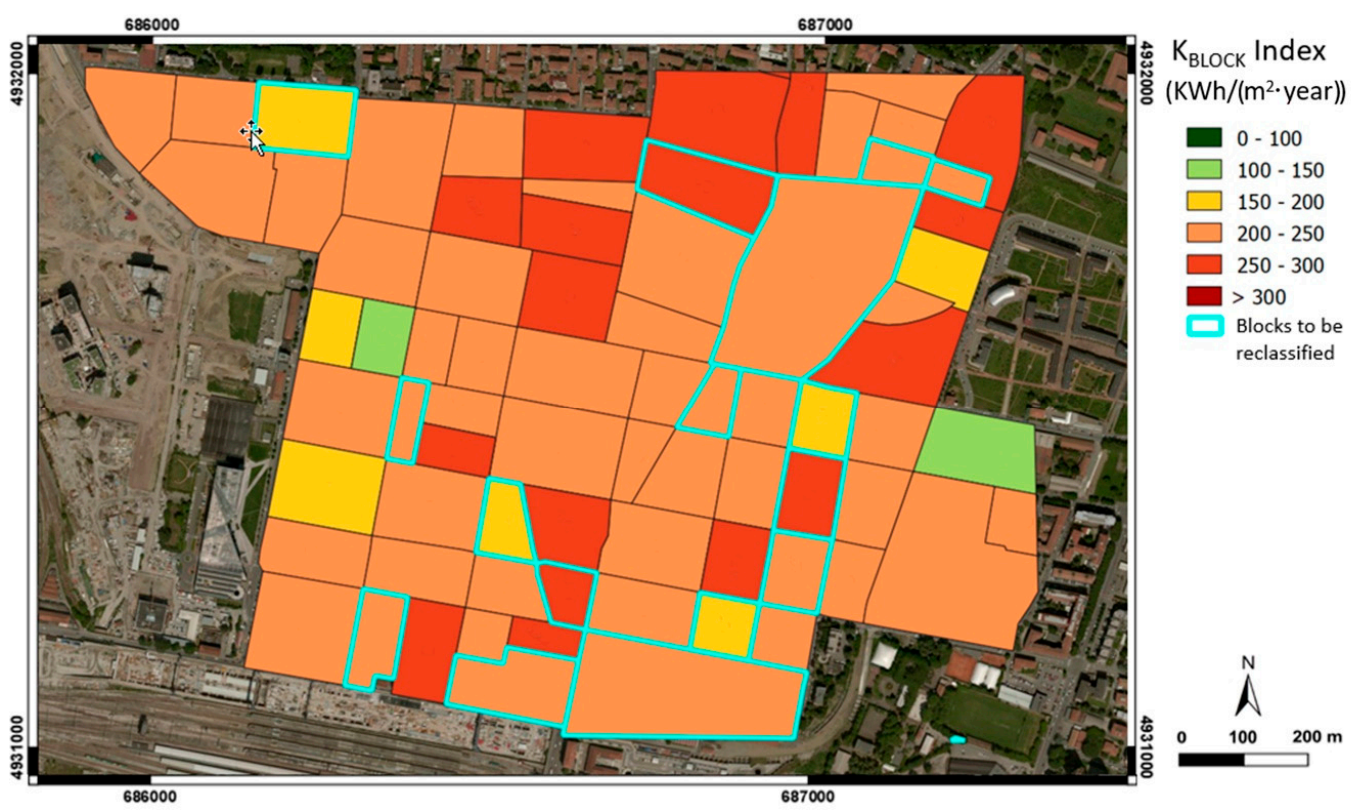

Figure 6. The $\mathrm{K}_{\mathrm{BLOCK}}$ index map corresponding to the validation area (Bolognina) at block scale. Bing aerial imagery is used as the base map.

\section{Discussion}

The structure and the stages of the proposed methodological approach clearly reflect the constraints regarding the input data availability, particularly the need to properly set the basic unit on which the study focuses. Within the energy efficiency field, this typically refers to the building scale, which may be coherent with the initial request to obtain a picture of the stock that does not meet the minimum energy efficiency requirements but does not fit well with the scope that instead clearly aims to easily visualize and process data about energy consumption distribution at the district/city scales. The building level is a consolidated basic unit adopted both in GIS and building information modeling (BIM) environments for modeling purposes, as clearly evidenced by the literature [66,67]. However, the limitations of EPCs, due to data protection regulations that require treating data without a full address line (street and street number), obliged us to work at cadastral parcel scale and not at the building scale (the ownership of data may differ according to the context, and in other experiences full data were used according to specific agreements). The complete address and the street number code link each cadastral unit with the corresponding vector geometric element [68].

The MA and the research team took the sensitive data issue seriously from the very beginning, assuming that the methodology has to comply with the Legislative Decree 101, 10/08/2018 [36], that acknowledges the European General Data Protection Regulation 2016/679 [69] within the Italian territory. This is the reason why full address data were made available only for validation purpose on a sample area with limited extent, while the methods developed for using nonsensitive data have been instead applied $[70,71]$, complying with the strict nondisclosure agreement for data processing and considering that the generated outcome would display only aggregated data on the map.

The use of EPCs evidenced some other issues concerning the collection methodology and the data storage organization. EPCs were introduced by the Decree Law n.63 (04/06/2013) [72] and following updates, providing a specific template for all new and existing buildings to be rented or sold within the market. In 2015, some new standards were included in the template in order to make the energy performance classification more homogeneous, partially changing the recorded data structure or the data writing formats. Even though this aspect is not part of the present study, it seriously affected the way in which data have to be processed. Some differences were detected in datasets from 2009 to 2015 and those from 2015 to 2018, requiring additional steps for harmonization [73] during the preparation phase for GIS processing. A recurrent detected error regards the address writing format (names and 
numbers). The mismatch of the address formulation criteria between the EPC files used for validation and the available vector files obstructs a simultaneous analysis of the entire municipal territory. The frequent typo errors made it impossible to apply an automatic correction procedure, and most of the errors had to be manually amended. This was possible for the sample area (Bolognina), considering its limited extent, but could significantly impact the entire process if applied to the whole city.

As already evidenced by Hohmann [74], these problems suggest a reflection on data collection methods and organization within the MA, especially considering the new three-year plan for information technology in the Public Administration aiming to achieve the digital transformation of the Italian PAs in accordance with the European Digital Agenda programming [75].

Among the detected errors within the EPC files, the one regarding the lack of cadastral data or addresses can be very critical causing the loss of records (which in the specific case study was limited to $5 \%$ ) and related visualization in the energy map. The lack of geometric congruence between some vector files (such as between building vector and block boundaries vector) can be instead solved by the application of some spatial GIS tools [76].

Taking into account all these limitations, the developed methodology tried to find adequate solutions to generate the energy maps: the $\mathrm{K}$ index map was initially obtained at the building scale and then obtained at the cadastral parcel scale, with more than $50 \%$ of total geometric units classified.

The number of EPCs used to calculate the K index (referring to the individual cadastral parcel) may vary in each cadastral parcel, consequently the $\mathrm{K}$ index of a cadastral parcel can be calculated only as a part of all of the urban units or a part of all buildings included within it. The progressive increase of EPC availability will definitely improve the map reliability until a total coverage is finally achieved. Considering that the available EPCs (covering the time period up to 2018) represent $50 \%$ of the urban units (assuming a relevant part of the residual 50\% belongs to a building typology that does not require an EPC, as already explained), the developed methodology could be positively refined and implemented during the coming years in order to increase its levels of precision and efficiency.

If the results are observed at the block scale, the K index improves in terms of quality: $88 \%$ of the blocks have an associated K-value. Since this scale is more aligned with the planning purposes discussed with the PA, the validation process was performed at the block scale: $80 \%$ of the blocks have an associated class corresponding to the $\mathrm{K}$ index classification range. Regarding the gap between the two results (conventional methodology and validation), the following considerations can be reported:

- Despite both the conventional and the validation processes using EPCs as input data, the validation does not consider the building step, instead only considering the cadastral parcels in a single step.

- The EPC dataset made available during the validation included 20,000 more records (referring to part of 2018 and 2019), which produced some differences as highlighted in Figures 5 and 6.

- The limited extent of the sample area during the validation process allowed to manually amend some detected errors which otherwise would become a very time-consuming activity if the whole city territory would be involved.

Based on the overall outcomes and these observations, the achieved result was considered to be satisfactory by the MA and the team with relation to the initial research brief.

\section{Conclusions}

Considering all the premises as well as the limitations and barriers that arose during the study with relation to input data, it has to be honestly said that the outcome confirms the constraints and difficulties already mentioned by the scientific literature. However, the result can be considered a step forward in shifting the perspective from the individual building energy performance to a wider urban energy consumption observation, which was the main requirement of the regional regulation update. This will allow the MA to focus on specific measures where energy intensity concentration requires greater attention or to customize solutions with relation to specific situations. It is also very relevant for launching initiatives (such as incentives or bonus) able to boost a diffuse improvement 
linked to specific typologies. Much more relevantly, it will be very helpful in monitoring the overall situation detecting where lack of data and information are concentrated as well as in obtaining updated maps which will provide easy-to-visualize feedback of the impact derived by the decisions and energy policies adopted over a time period.

The methodological approach used for generating the $\mathrm{K}$ index map can be considered a valid and effective starting point for further detailed elaboration of energy performance maps, taking into account data reliability as an open issue to be further investigated. This can be considered a feasible and realistic goal, assuming that the continuous update of EPCs will make new input data available to feed the methodology, improving its precision and reliability. This will help in taking into account the evolution of energy consumption of buildings over time, keeping the focus on the overall demand and distribution at the city level and supporting reflections on the influence of local and external conditions (such as the effects of climate change). The main benefit deriving from this study lies in the opportunity of using maps to represent a systemic and easy-to-visualize picture of energy consumption at the city level that policy-makers and designers can use to support the decision-making process as well as to easily communicate the outcomes to citizens and end-users, improving the collective level of awareness towards this topic.

It also has to be noted that the described methodology can be generalized and easily replicated in other contexts without its main structure changing, even if the outcomes can be of course affected by the quality of available data and resources. With that being said, this methodology represents an opportunity to explore the energy consumption trends at the city/district scales and consequently address future measures and initiatives to foster energy savings.

Author Contributions: Conceptualization, J.G.; methodology, J.G., E.A., M.D.G.; software, M.D.G.; validation, J.G., E.A., M.D.G.; formal analysis, J.G., E.A., M.D.G.; investigation, J.G., E.A., M.D.G., V.V.; resources, J.G., E.A., M.D.G., V.V.; data curation, M.D.G.; writing—original draft preparation, M.D.G.; writing—review and editing, J.G. and E.A.; visualization, M.D.G.; supervision, J.G. and E.A.; project administration, J.G. All authors have read and agreed to the published version of the manuscript.

Funding: This research was partially funded by Emilia-Romagna Region, within the framework research program titled "Efficienza energetica in edilizia e nel settore industriale" (G.R. 17147/2017, G.R. 19429/2017) supported by the "Piano triennale integrato Fondo Sociale Europeo (FSE), Fondo Europeo di Sviluppo Regionale (FESR) e Fondo Europeo Agricolo per lo Sviluppo Rurale (FEASR) - Alte Competenze per la ricerca, il trasferimento tecnologico e l'imprenditorialità" funding scheme.

Acknowledgments: The authors express their sincere gratitude to V. Orioli, F. Evangelisti, G. Fini, F. Tutino, C. Girotti, C. Manaresi and those who gave their support and their contribution within the Municipality of Bologna.

Conflicts of Interest: The authors declare no conflict of interest.

\section{References}

1. Directive 2012/27/EU of the European Parliament and of the Council of 25 October 2012 on Energy Efficiency, Amending Directives 2009/125/EC and 2010/30/EU and Repealing Directives 2004/8/EC and 2006/32/EC. Available online: https://eur-lex.europa.eu/legal-content/EN/TXT/?uri=celex\%3A32012L0027 (accessed on 31 October 2019).

2. Directive 2010/31/EU of the European Parliament and of the Council of 19 May 2010 on the Energy Performance of Buildings (Recast). Available online: https://eur-lex.europa.eu/legal-content/EN/TXT/?uri= CELEX\%3A32010L0031 (accessed on 31 October 2019).

3. Bhargavi, P.; Jyothi, S. Soil Classification Using Data Mining Techniques: A Comparative Study. Int. J. Eng. Trends Technol. 2011, 2, 55-59.

4. Cai, G. Contextualization of Geospatial Database Semantics for Human-GIS Interaction. Geoinformatica 2007, 11, 217-237. [CrossRef]

5. Fonseca, M.E. Using ontologies for integrated geographic information systems. Trans. Gis. 2002, 6, 231-257. [CrossRef]

6. Jones, C.B.; Alani, H.; Tudhope, D. Geographical Information Retrieval with Ontologies of Place; COSIT 2011; Montello, D.R., Ed.; LNCS: Berlin/Heidelberg, Germany, 2001; Volume 2205, pp. 322-335. 
7. Lee, A.J.T.; Chen, Y.A.; Ip, W.C. Mining frequent trajectory patterns in spatial-temporal databases. Inform. Sci. 2009, 179, 2218-2231. [CrossRef]

8. Ravikumar, G.; Sivareddy, M. An Effective Analysis of Spatial Data Mining Methods Using Range Queries. J. Glob. Res. Comput. Sci. 2012, 3, 7-12.

9. Van Cleef, E. Cities in Action; Pergamon Press: New York, NY, USA, 1970.

10. Fischel, W.A. The Evolution of Zoning Since the 1980s: The Persistence of Localism. In Property in Land and Other Resources; Cole, D.H., Ostrom, E., Eds.; Lincoln Institute of Land Policy: Cambridge, MA, USA, 2010; pp. 288-293.

11. Erickson, A. The Birth of Zoning Codes, a History. 2012. Available online: https://www.citylab.com/equity/ 2012/06/birth-zoning-codes-history/2275/ (accessed on 15 April 2020).

12. Trombadore, A. MEETHINK Energy Project A research experience. Mediterr. Smart Cities 2016, 1, 85.

13. Caputo, P.; Costa, G.; Ferrari, S. A supporting method for defining energy strategies in the building sector at urban scale. Energy Policy 2013, 55, 261-270. [CrossRef]

14. Theodoridou, I.; Karteris, M.; Mallinis, G.; Papadopoulos, A.M.; Hegger, M. Assessment of retrofitting measures and solar systems' potential in urban areas using Geographical Information Systems: Application to a Mediterranean city. Renew. Sustain. Energy Rev. 2012, 16, 6239-6261. [CrossRef]

15. Heiple, S.; Sailor, D.J. Using building energy simulation and geospatial modeling techniques to determine high resolution building sector energy consumption profiles. Energy Build 2008, 40, 1426-1436. [CrossRef]

16. Hill, L. Georeferencing: The Geographic Associations of Information; MIT Press: Cambridge, MA, USA, 2009.

17. Zheng, Y.; Zha, Z.; Chua, T. Research and Applications on Georeferenced Multimedia: A Survey. Multimed. Tools Appl. 2011, 51, 77-98. [CrossRef]

18. Hackeloeer, A.; Klasing, K.; Krisp, J.M.; Meng, L. Georeferencing: A review of methods and applications. Ann. GIS 2014, 20, 61-69. [CrossRef]

19. Leidner, J. Georeferencing: From texts to maps. Int. Encycl. Geogr. 2016, 1-10. [CrossRef]

20. Reiter, S.; Wallemacq, V. City energy management: A case study on the area of Liège in Belgium. In Proceedings of the International Conference GEOProcessing 2011; Rückemann, C.P., Wolfson, O., Eds.; IARIA: Wilmington, NC, USA, 2011; pp. 1-6.

21. Balta, C. GIS-Based Energy Consumption Mapping. Master's Thesis, Edinburgh Research Archive, Edinburgh, UK, 2014.

22. Voigt, P.; Von dem Bussche, A. The EU General Data Protection Regulation (GDPR). A Practical Guide, 1st ed.; Springer International Publishing: Cham, Switzerland, 2017.

23. Resch, B.; Sagl, G.; Törnros, T.; Bachmaier, A.; Eggers, J.B.; Herkel, S.; Gündra, H. GIS-based planning and modeling for renewable energy: Challenges and future research avenues. ISPRS Int. J. Geo. Inf. 2014, 3, 662-692. [CrossRef]

24. Calvert, K. From 'energy geography' to 'energy geographies' Perspectives on a fertile academic borderland. Prog. Hum. Geogr. 2016, 40, 105-125. [CrossRef]

25. Li, C. GIS for Urban Energy Analysis. In Comprehensive Geographic Information Systems; Huang, B., Ed.; Elsevier: Oxford, UK, 2018; pp. 187-195.

26. Parshall, L.; Gurney, K.; Hammer, S.A.; Mendoza, D.; Zhou, Y.; Geethakumar, S. Modeling energy consumption and $\mathrm{CO} 2$ emissions at the urban scale: Methodological challenges and insights from the United States. Energy Policy 2010, 38, 4765-4782. [CrossRef]

27. Van Hoesen, J.; Letendre, S. Evaluating potential renewable energy resources in Poultney, Vermont: A GIS-based approach to supporting rural community energy planning. Renew. Energy 2010, 35, 2114-2122. [CrossRef]

28. Guttikunda, S.K.; Calori, G. A GIS based emissions inventory at $1 \mathrm{~km} \times 1 \mathrm{~km}$ spatial resolution for air pollution analysis in Delhi, India. Atmos. Environ. 2013, 67, 101-111. [CrossRef]

29. Ascione, F.; Masi, R.F.; De Rossi, F.; Fistola, R.; Sasso, M.; Vanoli, G.P. Analysis and diagnosis of the energy performance of buildings and districts: Methodology, validation and development of Urban Energy Maps. Cities 2013, 35, 270-283. [CrossRef]

30. Quan, S.J.; Li, Q.; Augenbroe, G.; Brown, J.; Yang, P.P.J. Urban data and building energy modelling: A GIS-based urban building energy modelling system using the urban-EPC engine. In Planning Support Systems and Smart Cities; Stan Geertman, S., Ferreira, J., Goodspeed, R., Stillwell, J., Eds.; Springer International Publishing: Cham, Switzerland, 2015; pp. 447-469. 
31. Gupta, R.; Gregg, M. Targeting and modelling urban energy retrofits using a city-scale energy mapping approach. J. Clean. Prod. 2018, 174, 401-412. [CrossRef]

32. Gupta, R.; Gregg, M. Local Energy Mapping Using Publicly Available Data for Urban Energy Retrofit. In Building Information Modelling, Building Performance, Design and Smart Construction; Dastbaz, M., Gorse, C., Moncaster, A., Eds.; Springer International Publishing: Cham, Switzerland, 2019; pp. 207-219.

33. Fabbri, K.; Zuppiroli, M.; Ambrogio, K. Heritage buildings and energy performance: Mapping with GIS tools. Energy Build. 2012, 48, 137-145. [CrossRef]

34. Fabbri, K. Building and fuel poverty, an index to measure fuel poverty: An Italian case study. Energy 2015, 89, 244-258. [CrossRef]

35. Mattinen, M.K.; Heljo, J.; Vihola, J.; Kurvinen, A.; Lehtoranta, S.; Nissinen, A. Modeling and visualization of residential sector energy consumption and greenhouse gas emissions. J. Clean. Prod. 2014, 81, 70-80. [CrossRef]

36. Legislative Decree 10/08/2018, n. 101. Disposizioni per L'adeguamento della Normativa Nazionale alle Disposizioni del Regolamento (UE) 2016/679 del Parlamento Europeo e del Consiglio, del 27 Aprile 2016, Relativo alla Protezione delle Persone Fisiche con Riguardo al tRattamento dei Dati Personali, Nonche' alla Libera Circolazione di Tali Dati e Che Abroga la Direttiva 95/46/CE (Regolamento Generale Sulla Protezione Dei Dati). Available online: https://www.gazzettaufficiale.it/eli/id/2018/09/04/18G00129/sg (accessed on 10 November 2019).

37. Kolter, J.Z.; Johnson, M.J. REDD: A public data set for energy disaggregation research. In Workshop on Data Mining Applications in Sustainability (SIGKDD); Citeseer: San Diego, CA, USA, 2011; Volume 25, pp. 59-62.

38. Porse, E.; Derenski, J.; Gustafson, H.; Elizabeth, Z.; Pincetl, S. Structural, geographic, and social factors in urban building energy use: Analysis of aggregated account-level consumption data in a megacity. Energy Policy 2016, 96, 179-192. [CrossRef]

39. Tronchin, L.; Fabbri, K. Energy Performance Certificate of building and confidence interval in assessment: An Italian case study. Energy Policy 2012, 48, 176-184. [CrossRef]

40. Murphy, L. The influence of the energy performance certificate: The Dutch case. Energy Policy 2014, 67, 664-672. [CrossRef]

41. Ballarini, I.; Corgnati, S.P.; Corrado, V. Use of reference buildings to assess the energy saving potentials of the residential building stock: The experience of TABULA project. Energy Policy 2014, 68, 273-284. [CrossRef]

42. Ballarini, I.; Corgnati, S.P.; Corrado, V.; Talà, N. Definition of building typologies for energy investigations on residential sector by TABULA IEE-project: Application to Italian case studies. Roomvent Trondheim 2011, $19-22$.

43. Loga, T.; Stein, B.; Diefenbach, N. TABULA building typologies in 20 European countries-Making energy-related features of residential building stocks comparable. Energy Build. 2016, 132, 4-12. [CrossRef]

44. Escrivá-Escrivá, G.; Álvarez-Bel, C.; Peñalvo-López, E. New indices to assess building energy efficiency at the use stage. Energy Build. 2011, 43, 476-484. [CrossRef]

45. Do, H.; Cetin, K.S. Residential Building Energy Consumption: A Review of Energy Data Availability, Characteristics, and Energy Performance Prediction Methods. Curr. Sustain. Renew. Energy Rep. 2018, 5, 76-85. [CrossRef]

46. Hong, T.; Taylor, L.S.C.; D'Oca, S.; Yan, D.; Corgnati, S.P. Advances in research and applications of energy-related occupant behavior in buildings. Energe Build. 2016, 116, 694-702. [CrossRef]

47. Cetin, K.S.; Siemann, M.; Sloop, C. Disaggregation and future prediction of monthly residential building energy use data using localized weather data network. 2016 ACEEE Summer Study Energy Effic. Build. 2016, 12, 1-12.

48. Wilde, P. The gap between predicted and measured energy performance of buildings: A framework for investigation. Autom Constr. 2014, 41, 40-49. [CrossRef]

49. Maantay, J.; Ziegler, J.; Pickles, J. GIS for the Urban Environment; Esri Press: Redlands, CA, USA, 2006.

50. ISTAT, Statistiche Demografiche ISTAT. Available online: http://demo.istat.it/bilmens2019gen/index.html (accessed on 31 March 2019).

51. Bernabei, G.; Gresleri, G.; Zagnoni, S. Bologna Moderna 1860-1980; Patron: Bologna, Italy, 1984.

52. Alaimo, A. L'organizzazione della Città: Amministrazione Comunale e Politica Urbana a Bologna Dopo l'Unità (1859-1889); Il Mulino: Bologna, Italy, 1990. 
53. Bazzoli, N. Frammentazione Urbana e Nuove Dinamiche Insediative. Bologna e il Suo Hinterland. Sguardi sul Mondo. Percorsi di Geografia Sociale; Patron: Bologna, Italy, 2014; pp. 215-224.

54. BLEUAP. Bologna Local Urban Environment Adaptation Plan for a Resilient City. Available online: http://www.blueap.eu/site/ (accessed on 15 June 2019).

55. TABULA WebTool. Available online: http://webtool.building-typology.eu/\#bm (accessed on 10 April 2019).

56. Gazzetta Ufficiale. Available online: https://www.gazzettaufficiale.it/eli/id/2013/08/03/13G00133/sg (accessed on 31 October 2019).

57. Economidou, M. (Ed.) Europe's Buildings under the Microscope. A Country-by-Country Review of the Energy Performance of Buildings; Buildings Performance Institute Europe: Brussels, Belgium, 2011.

58. Braulio-Gonzalo, M.; Bovea, M.D.; Ruá, M.J.; Juan, P. A methodology for predicting the energy performance and indoor thermal comfort of residential stocks on the neighbourhood and city scales. A case study in Spain. J. Clean. Prod. 2016, 139, 646-665. [CrossRef]

59. Mastrucci, A.; Baume, O.; Stazi, F.; Leopold, U. Estimating energy savings for the residential building stock of an entire city: A GIS-based statistical downscaling approach applied to Rotterdam. Energy Build. 2014, 75, 358-367. [CrossRef]

60. Droutsa, K.G.; Kontoyiannidis, S.; Dascalaki, E.G.; Balaras, C.A. Mapping the energy performance of hellenic residential buildings from EPC (energy performance certificate) data. Energy 2016, 98, 284-295. [CrossRef]

61. Liu, Y.; Yang, L.; Zheng, W.X.; Liu, T.; Zhang, X.R.; Liu, J.P. A novel building energy efficiency evaluation index: Establishment of calculation model and application. Energy Convers. Manag. 2018, 166, 522-533. [CrossRef]

62. Pérez-Lombard, L.; Ortiz, J.; Rodríguez Maestre, I. A review of benchmarking, rating and labelling concepts within the framework of building energy certification schemes. Energy Build. 2009, 41, 272-278. [CrossRef]

63. Hai, Z.; Frédéric, M. A review on the prediction of building energy consumption. Renew Sustain. Energy Rev. 2012, 16, 3586-3592.

64. Codd, E.F. A relational model of data for large shared data banks. Commun. ACM 1970, 13, 377-387. [CrossRef]

65. Bologna Municipality. Available online: http://umap.openstreetmap.fr/it/map/sezioni-di-censimentobologna_125580\#15/44.4954/11.3397 (accessed on 20 February 2020).

66. Ham, Y.; Golparvar-Fard, M. Mapping actual thermal properties to building elements in gbXML-based BIM for reliable building energy performance modelling. Autom. Constr. 2015, 49, 214-224. [CrossRef]

67. Davila, C.C.; Reinhart, C.F.; Bemis, J.L. Modeling Boston: A workflow for the efficient generation and maintenance of urban building energy models from existing geospatial datasets. Energy 2016, 117, 237-250. [CrossRef]

68. ESRI. GIS to Meet Renewable Energy Goals. Available online: http://www.esri.com/news/arcnews/ fall09articles/gis-to-meet.html (accessed on 3 November 2019).

69. Regulation (EU) 2016/679 of the European Parliament and of the Council of 27 April 2016 on the Protection of Natural Persons with Regard to the Processing of Personal data and on the Free Movement of Such Data, and Repealing DIRECTIVE 95/46/EC (General Data Protection Regulation). Available online: https: //eur-lex.europa.eu/eli/reg/2016/679/oj (accessed on 3 November 2019).

70. Pencarrick Hertzman, C.; Meagher, N.; McGrail, K.M. Privacy by Design at Population Data BC: A case study describing the technical, administrative, and physical controls for privacy-sensitive secondary use of personal information for research in the public interest. J. Am. Med. Inform. Assoc. 2012, 20, 25-28. [CrossRef]

71. Gholami, A.; Laure, E. Security and privacy of sensitive data in cloud computing: A survey of recent developments. arXiv 2016, arXiv:1601.01498. [CrossRef]

72. Legislative Decree 04/06/2013, n. 63. Disposizioni Urgenti per il Recepimento della Direttiva 2010/31/UE del Parlamento Europeo e del Consiglio del 19 Maggio 2010, Sulla Prestazione Energetica nell'edilizia per la Definizione delle Procedure D'infrazione Avviate dalla Commissione Europea, Nonche' Altre disposizioni in Materia di Coesione Sociale. Available online: https://www.gazzettaufficiale.it/eli/id/2013/06/05/13G00107/sg (accessed on 10 November 2019).

73. Nijssen, G.M. Modelling in Data Base Management Systems; North-Holland Pubnlishing: Amsterdam, The Netherlands, 1976. 
74. Hohmann, L.; Rappapor, I.S.; Schnitz, M.; Rosenquis, B.; Jackson, A. Intellectual Asset Protocol for Defining Data Exchange Rules and Formats for Universal Intellectual Asset Documents, and Systems, methods, and Computer Program Products related to Same. U.S. Patent Application No. 7,437,471, 2 March 2008.

75. AGID (Agenzia per 1'Italia Digitale). Available online: https://www.agid.gov.it\T1\guilsinglrightrepository_ files\T1\guilsinglrightPiano-Triennale-ICT-2019-2021 (accessed on 3 December 2019).

76. QuantumGis Tutorial. Available online: https://docs.qgis.org/testing/en/docs/training_manual/ (accessed on 3 December 2019).

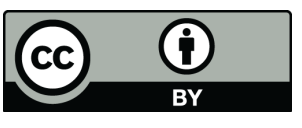

(C) 2020 by the authors. Licensee MDPI, Basel, Switzerland. This article is an open access article distributed under the terms and conditions of the Creative Commons Attribution (CC BY) license (http://creativecommons.org/licenses/by/4.0/). 